\section{DIGITAL COMMONS \\ @ UNIVERSITY OF SOUTH FLORIDA}

\section{ABO: Interactive Journal for Women in the Arts, 1640-1830}

Volume 2

Issue 2 Volume 2.2 (Fall 2012): Open Access

Article 5

2012

\title{
Cultivating Resources in Hard Times
}

Catherine Ingrassia

Virginia Commonwealth University, cingrass@vcu.edu

Follow this and additional works at: https://digitalcommons.usf.edu/abo

Part of the Dramatic Literature, Criticism and Theory Commons, Educational Methods Commons, Feminist, Gender, and Sexuality Studies Commons, and the Literature in English, British Isles Commons

\section{Recommended Citation}

Ingrassia, Catherine (2012) "Cultivating Resources in Hard Times," ABO: Interactive Journal for Women in the Arts, 1640-1830: Vol.2: Iss.2, Article 5.

http://dx.doi.org/10.5038/2157-7129.2.2.5

Available at: https://digitalcommons.usf.edu/abo/vol2/iss2/5

This Scholarship is brought to you for free and open access by Digital Commons @ University of South Florida. It has been accepted for inclusion in ABO: Interactive Journal for Women in the Arts, 1640-1830 by an authorized administrator of Digital Commons @ University of South Florida. For more information, please contact digitalcommons@usf.edu. 


\section{Cultivating Resources in Hard Times}

\section{Keywords}

funding, higher education, institutional resources, mentoring, state of the profession, women

Creative Commons License

(c) $($ ) $\odot$

This work is licensed under a Creative Commons Attribution-No Derivative Works 3.0 License. 
Last April at the annual meeting of the American Society for Eighteenth-Century Studies, I was on two panels that each dealt with the current "hard times" we are experiencing in higher education. Those challenges are keenly felt by scholars and teachers in the (often already feminized) humanities and especially, I would argue, by female faculty members of all ranks. As Judith Glazer-Raymo describes in Unfinished Agendas, the changing economic, political, and social climate in the United States now "threatens to reverse many of women's hard-earned gains [in academia] of the past thirty-six years” (xii). Gender and discipline (and, of course, gendered disciplines) define our identities within an institution and, as a result, our capacity to affect the kinds of changes or achieve the kinds of results we seek. Within academic institutions, which we know are profoundly hierarchical structures, women, like humanists, are often under-represented within administrative ranks where decisions about resource allocation, recruitment and retention, and promotion and tenure are made. During six years of service as the executive associate dean in the College of Humanities and Sciences at a large, public urban research university, I observed the frustration my colleagues experienced in their pursuit of institutional funding, witnessed (and tried to alleviate) some of the obstacles in my female colleagues' career trajectory, and studied the often stark divide in attitudes between administrators (usually men drawn from the sciences or social sciences) and faculty in the humanities. Securing resources as a humanist and progressing professionally as a woman both demand we shed some of our disciplinary assumptions while also using the tools that define us as scholars - research and analysis-to position ourselves to get things done in hard times. What follows is a series of suggestions on securing financial resources from your institution and on ensuring that your institution is creating an environment in which you can cultivate your own resources as a faculty member.

\section{Educate yourself about the publicly stated priorities of your institution and figure out how you and your research fit. In these days of accountability, assessment, and financial limitations, all universities have or are creating strategic plans. While these documents contain lofty statements about mission, they're basically a statement justifying the spending they will or will not do-the "resource allocation." A strategic plan serves as a blueprint for the institution, with specific goals or "metrics" by which "performance" will be measured. If your institution is in the process of creating its strategic plan, attend sessions related to that process or better yet get yourself placed on the planning committee. If a strategic plan already exists, read it carefully (and not just the executive summary). Any proposal for funding you write needs to connect to at least one of those stated priorities. This suggestion is not designed to encourage you to misrepresent your activities; rather, it is designed to have you consider how, by presenting your work in language consistent with stated institutional priorities, you can enhance your chair or dean's ability to demonstrate a "meeting" of those goals and in turn your ability to secure funding.}

Learn how funding works at your institution. If you teach at a public institution, financial information about expenditure of state-funded dollars is a matter of public record. Figure out how money is allocated at your institution. Even when institutions say there is no money, there is still always money. Understand how your institution works 
well enough to identify potential sources of money and the individuals responsible for allocating those dollars. Many universities have professional development opportunities for faculty or new administrators-attending those or reviewing the supplemental materials can provide you with some key information about how things work. You can also learn what different kinds of funds exist (state-allocated resources, unrestricted dollars, overhead returned from external grants, etc.). When making the transition from a humanities faculty member to an administrator at the college level, I quickly recognized the fundamentally different assumptions and attitudes that guided the requests from and decisions of other disciplines (and administrators) in relation to finance. It reinforced the fact that the humanities are a research bargain, a statement that cannot be made too often to administrators at the dean's level and above. At research universities, departments in the sciences routinely spend on start-up for one newly hired Ph.D. an amount of money that could be used to purchase significant digital databases (e.g., ECCO) or support the research of about a dozen humanities faculty. Only when you really see how all the money is spent can you begin to be fully informed about how to advocate for resources.

Understand who to ask and cultivate that person or persons. Appropriately, most faculty turn initially to their chair when seeking resources, and they might be able to provide some limited assistance. However, chairs are often the least empowered individuals in an institution, especially in terms of resources. They have a tremendous amount of responsibility but, ultimately, little real authority. Look instead at the next level at your institution-those deans, associate deans, and directors who control budgets. These are the people to approach with your proposal or idea, or the individual with whom to have an informational conversation. Many of your colleagues will be hesitant to "bother" someone in the dean's office with certain requests or issues (and data suggests that women are less likely to ask for assistance), but in a functional administration, it's someone's job to help you get things done. You can't get what you don’t ask for.

\section{Realize that, as with comedy, so too with budget allocation--timing is everything.} You should always have a proposal ready because funding is cyclical. The request you make in September may not be fundable then; but, come May and the approaching end of the fiscal year, if an administrator has year-end dollars they need to spend, they can now say yes. Always continue to ask. No doesn't always mean no; sometimes it just means, not now, maybe later. This recommendation about timing is particularly important in the era of financial austerity; the tendency is for people to stop planning and stop being aspirational because the administrative line is "there's no money." That's a mistake both in the event that resources are restored and in your visibility to administrators.

Use the lingua franca of administrators - bullets and spreadsheets. When making a request, create a budget, not a written narrative-budgets are narratives. While it's important to have a written explanation or justification for any request you make, the people who can give you funds really just want the bottom line-the amount of the request and a brief statement of its significance and its connection to the strategic plan. Certainly you should have a more fully developed proposal, but be thinking in terms of brief, executive-summary-like requests. Administrators are inundated with paper and are grateful for brevity when appropriate. It also suggests you know what you're doing and 
dispels the all-too-common idea among administrators that humanities research doesn't translate.

Look for strategic opportunities for partnering within your institutions. If your university has an honors college, a center for teaching excellence, or any other specialized professional development unit, there is a good chance that entity has its own funding line. Research the unit, meet with the director or dean, and find out what the possibilities are. There may be an opportunity to have teaching help pay for your research through course release or a stipend, or it may take the form of small grants that are offered to develop courses or bring in a speaker. Think about how you can use those kinds of opportunities within your institution.

Create structured and sustained academic networks with colleagues across humanities disciplines. This kind of collaboration serves two crucial purposes. First, allied faculty can reiterate a crucial message that the humanities are a bargain and essential to any institution. We cannot stop making that message repeatedly and loudly to the highest levels of our academic administration. Second, and equally important, data indicate that female faculty (and probably all faculty) feel the greatest inspiration and reinvigoration when they reconnect with colleagues at conferences-ironic and frustrating at a time when travel dollars are eroding. Within our own institutions, spending time with colleagues outside of committee work and department meetings, simply for the purposes of discussing a journal article or sharing work-in-progress will often be the first thing that gives way to more "time-sensitive" activities. However, now more than ever, it is essential to make those a fundamental part of your regular professional activity and to use these opportunities to talk about work, plan for your unit, plot specific strategies, and offer much-needed support.

The suggestions above are directed toward the humanities faculty member seeking funding from administrators. However, our success in those efforts is enhanced either when we speak with the imprimatur of institutional approval (e.g., as a tenured associate or full professor) or when the person to whom we speak shares our disciplinary perspective. The way to create that situation is to work toward a climate in which women can maintain momentum in their academic path and, in turn, realize opportunities to assume positions of administrative responsibility within their institution. My final recommendations speak directly to that issue.

Institutions mentor the wrong faculty members, focusing on newly tenure-eligible faculty rather than the newly tenured ones. Among the important findings of the 2009 report of the MLA Committee on the Status of Women in the Profession, Standing Still: The Associate Professor Survey, is the fact that women are promoted from associate to full professor more slowly than men, regardless of their marital or parental status. Women at the rank of associate professor, in the title words of the report, "appear to be standing still in relation to men." ${ }^{1}$ Additionally, not only do women arrive at the rank of professor later than men, the time in the rank of associate professor is actually lengthening for women, and the situation is more prevalent at research-one universities. The failure to provide the structures - mentoring, professional networks, a receptive 
institutional culture- that demonstrably help women rise to the rank of full professor with greater speed is itself a contributing factor in the challenges that face women at all levels of an institution. Tenure creates a sense of responsibility (the old adage "now the real work begins"), yet it also provides institutional security that allows faculty to say no, to choose commitments strategically, to start new research, and to ask questions and demand answers that might previously have been too challenging or risky to pose. Recently tenured faculty face new demands on their time, more professional choices, and a precarious moment when it is easy to lose the momentum created by the usually fixed deadline of mandatory review for tenure and promotion.

But why does it matter whether a greater number of women populate the ranks of full professors? Certainly women at any rank can seek to be heard at an institution, but the reality of many institutions - even in an age of shared governance-is that full professors have an enhanced ability to mentor and assist younger colleagues, an increased credibility with administrators, and, like all tenured faculty, the academic and professional freedom to interrogate university policies and procedures that form the working conditions for all faculty. Unless and until the number of women increases among the professoriate and, in turn, administrative ranks at the highest levels, among the academic leadership and decision-making positions, we will be unable to affect the kinds of cultural change that will improve the situation for women at any stage of the profession. In turn, it will be difficult to help female scholars realize some consolidation of power, achieve an institutional and national voice, and restore some of the losses of the Great Recession. While a female president or provost may provide some limited opportunity for change, culture is not changed from the top down. Department chairs, deans, program heads, and, most importantly, colleagues are the ones who can really effect change and model behavior. Having women as an integral part of that process is essential for any real change.

To that end, let me make a final suggestion (with some caveats and conditions).

\section{Women should consider seeking or accepting some sort of administrative position.} If you are already spending a significant amount of time on service and if you either are or have a clear path to full professor, consider an administrative stint. Becoming an administrator for some period of time - as a program head, chair, director, or dean — can provide you with knowledge, insight, and strategies that will assist you and, equally important, assist your colleagues in seeking financial resources and shaping academic culture. And, if you already do a lot of "soft work" in the form of service, taking on a formal position with some sort of compensation (course release, summer stipend, or administrative supplement) can be helpful. ${ }^{2}$ However, never take an administrative position without an exit strategy, whether you are assuming a role as graduate director, chair, or dean. Term limits in administrative positions exist, when they exist, for many reasons and it really important to retain your credibility as a member of the faculty.

The situations these comments are meant to address are neither simple nor easily solved. However, with concerted effort and consistent, if incremental, change, we can successfully cultivate our professional resources. 


\section{Works Cited}

Babcock, Linda and Sara Laschever, Women Don't Ask: Negotiation and the Gender Divide. Princeton: Princeton University Press, 2003.

Glazer-Raymo, Judith. Unfinished Agendas: New and Continuing Gender Challenges in Higher Education. Baltimore: Johns Hopkins University Press, 2008.

Standing Still: The Associate Professor Survey Report of the Committee on the Status of Women in the Profession. 27 April 2009. Web.

$<$ http://www.mla.org/pdf/cswp_final042909.pdf >

\footnotetext{
${ }^{1}$ Publication occurred shortly before the economic downturn; thus many of the report's observations and recommendations were lost in the face of the most challenging financial climate in decades. Nationally, across all disciplines, women constitute little more than a third of full professors: 126, 515 men; 45,571 women. http://chronicle.com/article/Percentage-of-Faculty$\underline{\text { Members/128518/ }}$

${ }^{2}$ If embarking on an administrative path, however, women would be well-advised to read Linda Babcock and Sara Laschever’s Women Don't Ask: Negotiation and the Gender Divide.
} 